\title{
The role of awareness in affective information processing: An exploration of the Zajonc hypothesis
}

\author{
LOUIS G. TASSINARY, SCOTT P. ORR, GEORGE WOLFORD, \\ SHIRLEY E. NAPPS, and JOHN T. LANZETTA \\ Dartmouth College, Hanover, New Hampshire
}

\begin{abstract}
The present study explores the role of awareness in the processing of hedonically valent stimuli. We demonstrate that stimulus awareness is not necessary for stimulus valence either to elicit an affective response or to influence a subsequent cognitive decision. The results are interpreted as providing qualified support for Zajonc's hypothesis regarding the independence of affective and cognitive processing systems. However, we suggest that this simple dichotomy is in need of revision.
\end{abstract}

A few years back, Zajonc (1980) proposed that emotion and cognition are separate psychological systems, presumably controlled by separate and partially independent neural systems. The primary behavioral evidence for this position was and remains an aspect of the mere exposure phenomenon (e.g., Kunst-Wilson \& Zajonc, 1980). That is, because increased stimulus exposure increases judged liking over and above its effect on judged familiarity, Zajonc reasoned that affective responses can occur temporally prior to and independent of cognitive processing. As such, he held these data to be in conflict with theories of emotion that invoke cognitive processes as a necessary element in the generation of emotional states.

Aside from questions regarding this conceptual reasoning (e.g., Lazarus, 1981; Watts, 1983) and the fact that some of these conclusions derive from debatable statistical assumptions (Birnbaum \& Mellars, 1979a, 1979b; Moreland \& Zajonc, 1979), all of these studies remain open to the same criticisms that were leveled against experiments done in the late 1940s and 1950s on "subception" (Erickson, 1960; see Erdelyi, 1974, for a review). The strongest criticism of such studies was the argument that, even though subjects misreported the stimulus, partial information about the stimulus had been perceptually registered and was sufficient to drive a subsequent affective response. Given that awareness has been operationalized as just below or at recognition threshold, this criticism is difficult to refute.

The dichoptic backward-masking technique is not subject to this criticism. By presenting a stimulus to one eye and a pattern mask to the other at sufficiently short stimu-

These data were reported at the meeting of the Eastern Psychological Association in Baltimore, MD, April 1984. We wish to thank Carol A. Fowler for her helpful criticisms and comments on an earlier version of this article. Requests for reprints should be sent to the senior author, who is now at the Department of Psychology, Spence Laboratories of Psychology, University of Iowa, Iowa City, IA 52242. lus onset asynchronies (SOA), it is possible to present foveally a physically nondegraded stimulus that is below even the detection threshold of the perceiver. Using this technique in conjunction with a priming lexical decision paradigm, researchers have repeatedly demonstrated that perceivers can access the meanings of words that they are completely unaware of having seen (Balota, 1983; Fowler, Wolford, Slade, \& Tassinary, 1981; Marcel, 1983b).

The present study was designed to explore some implications of Zajonc's (1980) proposal by using this technique along with more direct manipulations and measures of affect. This specifically involved the use of a differential conditioning paradigm followed by a lexical decision task in which the CS +, CS - , and unassociated words served as primes. If, as Zajonc suggested, the occurrence of emotion is defined by the arousal of autonomic, visceral, glandular, and neuromuscular processes by virtue of an efficient emotional stimulus, support for his independence hypothesis would be obtained if these processes were evident in the absence of stimulus awareness. The single study in the literature that had examined the backward masking of conditioned stimuli (Ross, Ferreira, \& Ross, 1974) found no evidence of differential conditioned responses in the absence of awareness when measuring nonemotional overt responses. The present issue was of sufficient theoretical interest that we felt another attempt using different measures and a different paradigm was justified.

\section{METHOD}

\section{Subjects}

Twenty-four undergraduate students participated in the experiment for course credit.

\section{Stimuli and Dependent Measures}

Skin resistance (GSR), facial electromyographic signals (EMG) from the corrugator and masseter muscle regions, reaction time (RT), and accuracy (AC) were recorded by a laboratory microcomputer. Electric shock served as the unconditioned stimulus (UCS) and was delivered 
through a single electrode strapped to the calf of the subject's left leg. The GSR electrodes were attached to the subject's left palm, and the EMG electrodes were attached on the left side of his or her face. The conditioned stimuli (CSs) consisted of names of body parts and animals equated for word frequency and length. The unassociated words and target letter strings were taken from Fowler et al. (1981). The stimuli were displayed via a four-channel Gerbrands tachistoscope fitted with polarizing filters to allow dichoptic presentation of the stimulus materials.

The luminance level of the fixation field was set to $1.371 \mathrm{~cd} / \mathrm{m}^{2}$, and the luminance levels of the other three fields were set equal to $9.251 \mathrm{~cd} / \mathrm{m}^{2}$. Letter strings were drawn with a black marker on $5 \times$ 8 white cards with a Tektronix Plotter 4662 . All letters were uppercase and subtended vertical and horizontal visual angles of $.25^{\circ}$ and $.18^{\circ}$, respectively, when viewed in the tachistoscope. The letter strings subtended from $.64^{\circ}$ to $1.81^{\circ}$ of visual angle and were always centrally located in the viewing field. The pattern mask was the same as that used by Fowler et al. (1981) and consisted of superimposed uppercase letters.

\section{Procedure}

The subjects were run individually. They were first handed a set of instructions that outlined the event structure of the experiment. Any questions were answered and, after the GSR, EMG, and shock electrodes had been attached, the subject received a series of very brief shocks, the intensity of which began at near threshold and increased with each shock. The subject was asked to set a level of shock that was uncomfortable and highly annoying, but not painful. Once the shock level had been set, eye dominance was determined and the subject remained in the darkened room for several minutes while the experimenter checked the equipment and took several physiological readings. When the stimuli were loaded into the tachistoscope, the subject was allowed to initiate the trial by pressing a foot switch with his or her right foot. The intertrial interval was approximately $15 \mathrm{sec}$.

The subjects were assigned randomly to one of two CS + conditions (i.e., whether body parts or animal names were followed by shock) and to either the mask or the no-mask group.

The experiment was divided into two phases: conditioning trials and lexical decision trials. The initial conditioning trials consisted of eight presentations of each category, with shock administered after the first seven presentations of the CS + words. Both CS + and CS - words were presented for $500 \mathrm{msec}$.

The lexical decision phase consisted of 64 trials, evenly divided into word and nonword target trials. Thirty-two trials involved presentation of prime words for the CS + and CS - categories, half of which had previously been presented during acquisition. During this phase, the sequence differed for the mask and no-mask groups. Upon initiation of a trial, (1) the fixation mark remained on for $100 \mathrm{msec}$, (2) a prime word was presented to the nondominant eye for $10 \mathrm{msec}$, (3) a dark field was binocularly presented for $10 \mathrm{msec}$, (4) a pattern mask was presented to the dominant eye for $20 \mathrm{msec}$, (5) a dark field was binocularly presented for $1,460 \mathrm{msec}$, (6) a second letter string was binocularly presented for $500 \mathrm{msec}$, and (7) the fixation field returned for the duration of the intertrial interval. For the no-mask group, the prime was presented for $500 \mathrm{msec}$ to the dominant eye, no pattern mask was presented, and the dark field was presented for $1,500 \mathrm{msec}^{1}$

\section{RESULTS}

GSR was recorded at and EMG was integrated over .5 -sec intervals commencing $1.5 \mathrm{sec}$ prior to stimulus onset and ending $4 \mathrm{sec}$ later, producing 11 readings over a 5.5-sec period. GSR measurements were transformed into units of skin conductance (SCR) according to the formula SCR $=(1 /$ GSR $) \times 10^{6}$. Phasic response scores were obtained by computing the arithmetic difference between the mean for the first 2 readings and the 4th through 11 th readings, resulting in eight response scores per trial per measure. Each subject's phasic response scores were converted into $\mathrm{z}$ scores prior to data analysis. ${ }^{2}$

\section{Conditioning Trials}

Separate analyses of variance (ANOVAs) were conducted for each of the three physiological measures, with condition (mask, no-mask), readings (1-8), and stimuli $(\mathrm{CS}+, \mathrm{CS}-)$ as factors. The last $\mathrm{CS}-$ trial and the nonreinforced CS + trial were used as observations. Evidence of acquisition was found on all three measures, with either a significant main effect for stimuli (SCR, masseter) $[\mathrm{F}(1,22)=26.7303, \mathrm{p}<.0001$, and $\mathrm{F}(1,22)=4.8529$, $\mathrm{p}=.0366$, respectively] or a significant interaction of stimuli $\times$ readings $(\mathrm{SCR}$, corrugator) $[\mathrm{F}(7,154)=$ $12.1001, \mathrm{p}<.0001$, and $\mathrm{F}(7,154)=2.0858, \mathrm{p}=.0479$, respectively]. There were no significant interactions of stimuli with condition, demonstrating that prior to the lexical decision phase both mask and no-mask groups were equivalent in their affective responses to the CS + and CS - categories.

\section{Lexical Decision Trials}

Separate ANOVAs were conducted for each of five dependent measures (SCR, corrugator, masseter, RT, AC), with condition (no-mask, mask), readings (1-8), and prime type $(\mathrm{CS}+, \mathrm{CS}-)$ as factors for the physiological measures and condition, prime type, and target type (word, nonword) as factors for the RT measures.

For all three physiological measures, a significant readings effect occurred, as did significant three-way interactions (condition $\times$ prime type $\times$ readings) involving SCR and corrugator activity. Because of the mixed nature of the design, no generally agreed upon error term exists for examining the nature of these interactions. Consequently, separate analyses of variance were run on the mask and no-mask groups. The results of these analyses are as striking as they are counterintuitive.

For the no-mask group, physiological evidence of differential conditioning was observed only on the SCR measure, for which a significant readings $\times$ prime type interaction occurred $[F(7,77)=3.2459, p=.0046]$ (see Figures 1 and 2). The form of this interaction parallels that found at the end of acquisition. For the mask group, strong differentiation was observed on two of the physiological measures. A significant readings $\times$ prime type interaction occurred for corrugator activity $[F(7,77)=$ $3.4531, p=.003$ ], and both a main effect for prime type $[\mathrm{F}(1,11)=9.7042, \mathrm{p}=.0096]$ and a significant readings $\times$ prime type interaction $[\mathrm{F}(7,77)=5.3516, \mathrm{p}=$ $.0001]$ occurred on the SCR measure. Surprisingly, the pattern is the reverse of that seen during acquisition and found with the no-mask group, with subjects showing greater initial corrugator activity and a larger arousal response to the CS - category (see Figures 3 and 4).

Although there were no RT effects except for the expected facilitation of word over nonword decisions $[F(1,22)=23.9466, p=.0001]$, a marginally significant main effect for prime type did occur on the accuracy 


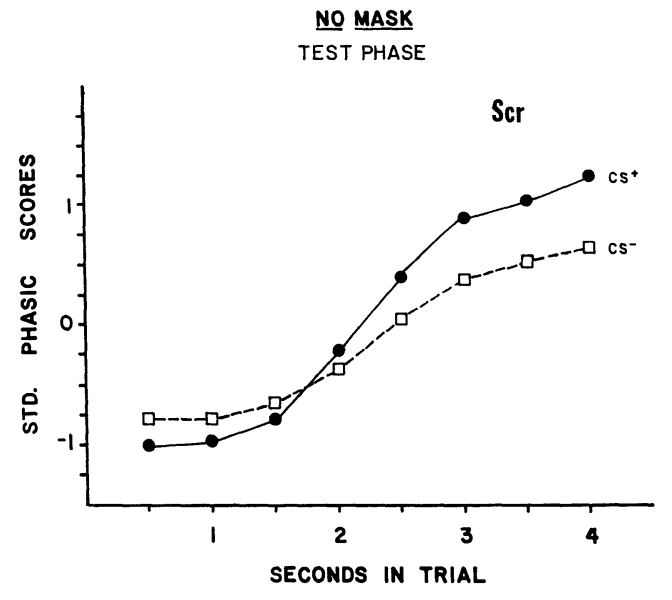

Figure 1. Mean phasic skin conductance response for the no-mask group as a function of prime type and time.

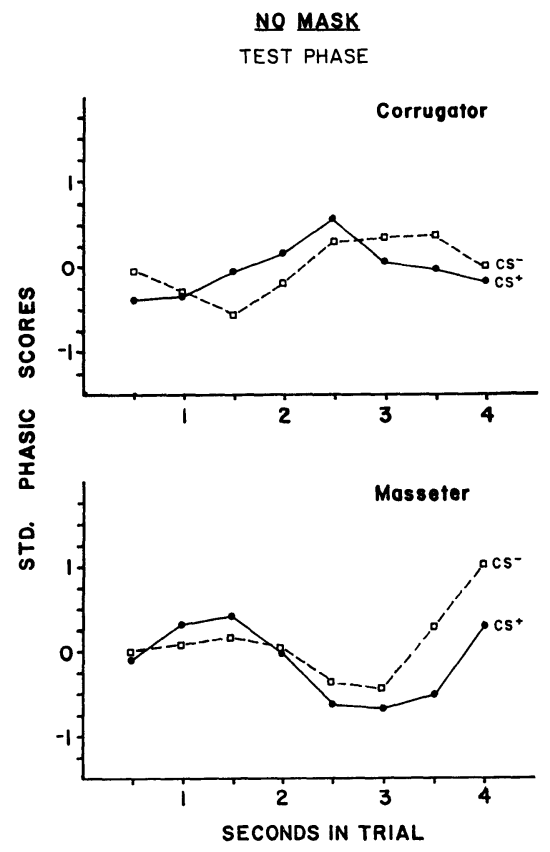

Figure 2. Mean phasic facial electromyographic response for the no-mask group as a function of prime type and time.

measure $[F(1,22)=4.0526, p=.054]$. For both mask and no-mask groups and for both words and nonwords, lexical decisions were significantly less accurate when preceded by a member of the CS + category. There is, however, a hint of a speed-accuracy tradeoff (see Figure 5).

\section{DISCUSSION}

Under masking conditions that preclude conscious awareness of the prime stimulus, strong physiological differential responses to CS + and CS - words did occur, suggesting that affective processing had taken place. In addition, the subjects were affected in a subsequent unrelated cognitive task in a way further suggesting that they were emotionally

\section{MASK}

TEST PHASE

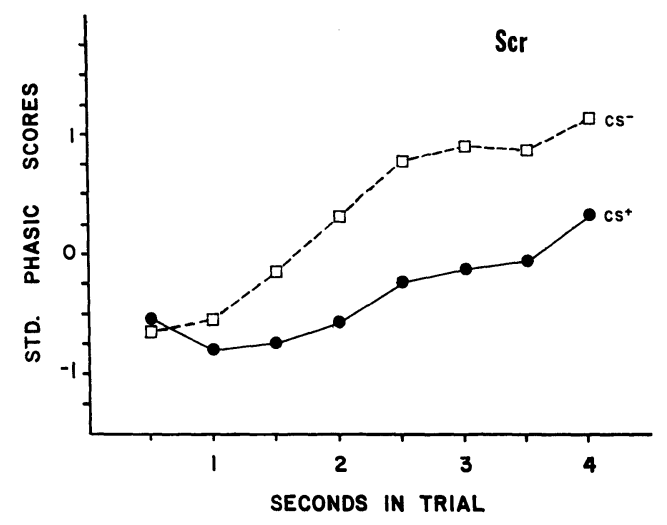

Figure 3. Mean phasic skin conductance response for the mask group as a function of prime type and time.

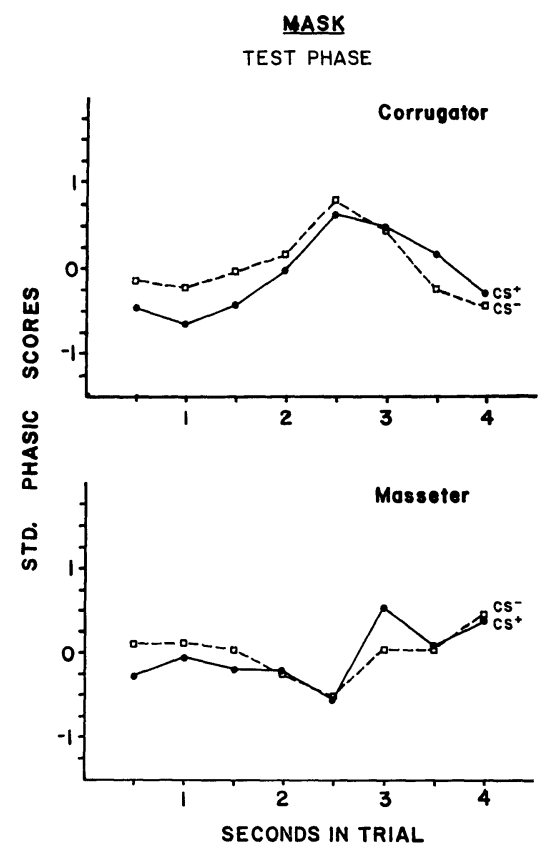

Figure 4. Mean phasic facial electromyographic response for the mask group as a function of prime type and time.

aroused by the presentation of the CS + category; that is, subsequent lexical decisions were faster and less accurate.

Although clear evidence of physiological differentiation was obtained in the mask condition, the data were anomalous in that the pattern was the reverse of that obtained in acquisition as well as in the test phase for the no-mask group. Although we cannot explain this reversal, it does suggest that awareness is necessary for normal, coordinated emotional responding.

In line with current perceptual theorists (e.g., Marcel, 1983a) and recent evidence (Balota, 1983; Fowler et al., 1981; Marcel, 1983b), we believe there is a real difference between cognitive processing with and without awareness. The present experiment extends this belief into the realm of affective processing. In support of Zajonc's (1980) proposal, we have presented evidence that the emotionality of a word can emerge in the absence of conscious detection. The studies of Balota (1983), Fowler et al. (1981), and Marcel (1983b) present evidence that the 


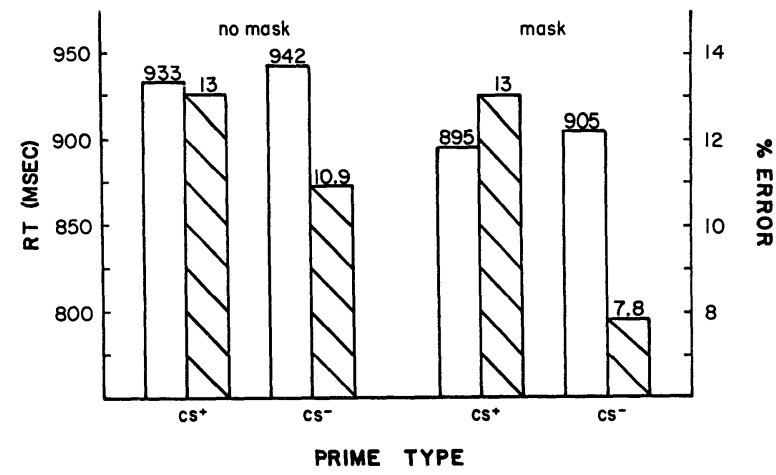

Figure 5. Mean RT and percentage error as a function of prime type for both the no-mask and mask groups.

lexical meaning of a word can also emerge in the absence of conscious detection. Clearly, the situation is far more complex and subtle than Zajonc proposed, for neither cognition nor emotion can be equated with conscious processing. The need is for detailed studies of the interaction between cognitive and emotional processes in the presence and absence of awareness, and for careful theoretical work on the exact nature of these processes. Given that subsequent experiments replicate this effect, we are now in possession of a paradigm with which to systematically investigate the components of emotional responding that do depend on conscious activity for their occurrence.

\section{REFERENCES}

Balota, D. A. (1983). Automatic semantic activation and episodic memory encoding. Journal of Verbal Learning and Verbal Behavior, 22, 88-104.

Birnbaum, M. H., \& Mellars, B. A. (1979a). One-mediator model of exposure effects is still viable. Journal of Personality and Social Psychology, 37, 391-394.

Birnbaum, M. H., \& Mellars, B. A. (1979b). Stimulus recognition may mediate exposure effects. Journal of Personality and Social Psychology, 37, 1090-1096.

Cheesman, J., \& Merikle, P. M. (in press). Priming with and without awareness. Perception \& Psychophysics.

ERDELYI, M. H. (1974). A new look at the new look: Perceptual defense and vigilance. Psychological Review, 81, 1-25.

ERICKSON, C. W. (1960). Discrimination and learning without awareness: A methodological survey and evaluation. Psychological Review, 67, 379-400.

Fowler, C. A., Wolford, G., Slade, R., \& TASSinary, L. G. (1981). Lexical access with and without awareness. Journal of Experimental Psychology: General, 110, 341-362.

Kunst-Wilson, W. R., \& Zajonc, R. B. (1980). Affective discrimination of stimuli that cannot be recognized. Science, 207, 557-558.
LAZARUS, R. S. (1981). Thoughts on the relations between emotion and cognition. American Psychologist, 37, 1019-1024.

MARCEL, A. J. (1983a). Conscious and unconscious perception: An approach to the relations between phenomenal experience and perceptual processes. Cognitive Psychology, 15, 238-300.

MARCEL, A. J. (1983b). Conscious and unconscious perception: Experiments on visual masking and word recognition. Cognitive Psychology, 15, 197-237.

MerikLE, P. M. (1983). Unconscious perception revisited. Perception \& Psychophysics, 31, 298-301.

MoReland, R. I., \& ZaJonc, R. B. (1979). Exposure effects may not depend on stimulus recognition. Journal of Personality and Social Psychology, 37, 811-821.

Nolan, K. A., \& Caramazza, A. (1982). Unconscious perception of meaning: A failure to replicate. Bulletin of the Psychonomic Society, 20, 23-26.

Purcell, D. G., Stewart, A. L., \& Stanovich, K. E. (1983). Another look at semantic priming without awareness. Perception \& Psychophysics, 34, 65-71.

Ross, L. E., Ferreira, C., \& Ross, S. M. (1974). Backward masking of conditioned stimuli: Effects on differential and single-cue classical conditioning performance. Journal of Experimental Psychology, 103, 603-613.

WATTS, F. N. (1983). Affective cognition: A sequel to Zajonc and Rachman. Behavior Research and Therapy, 21, 89-90.

ZaJonc, R. B. (1980). Feeling and thinking: Preferences need no inferences. American Psychologist, 35, 151-175.

\section{NOTES}

1. In recent years, a controversy has arisen in the literature as to the appropriate method for determining detection thresholds in paradigms such as this one (Merikle, 1983; Nolan \& Caramazza, 1982; Purcell, Stewart, \& Stanovich, 1983). Because of this controversy, detection thresholds were intentionally not determined for each subject prior to the actual experiment. Instead, uniformly low luminance levels and a single SOA (i.e., $20 \mathrm{msec}$ ) were used for all subjects. Both Cheesman and Merikle (in press) and Fowler et al. (1981), using very different psychophysical procedures, have found that comparable SOAs result in chance detection levels for most subjects after extensive threshold testing. By having limited the number of experimental trials, chosen a single SOA that nearly guaranteed chance detection for unpracticed subjects, and used low luminance levels, we are confident that our procedure effectively eliminated awareness of the prime stimulus in the mask group and are certain that it eliminated above-chance recognition performance. Informal questioning subsequent to the experiment revealed that all of the subjects in the no-mask group saw at least some percentage of the prime words, whereas none of the subjects in the mask group did so.

2. This transformation is appropriate for the present paradigm, since it allows for the elimination of between-subjects variation due to individual differences in responsiveness, while maintaining relative differences between phasic responses on CS + and CS - trials for each subject.

(Revision received for publication September 7, 1984.) 